CORRECTION

\title{
Correction to: Achieving financial stability during a liquidity crisis: a multi-objective approach
}

\author{
Edoardo Gaffeo ${ }^{1} \cdot$ Lucio Gobbi $^{1}$
}

Published online: 27 August 2021

(c) Springer Nature Limited 2021

\section{Correction to: Risk Management (2021) 23:48-74 https://doi.org/10.1057/s41283-021-00067-6}

The original version of this article unfortunately contained a mistake. First and last names of the authors were interchanged. The correct author names are given below. Given name: Edoardo; Family name: Gaffeo.

Given name: Lucio; Family name: Gobbi.

Publisher's Note Springer Nature remains neutral with regard to jurisdictional claims in published maps and institutional affiliations.

The original article can be found online at https://doi.org/10.1057/s41283-021-00067-6.

\section{Lucio Gobbi}

lucio.gobbi@unitn.it

1 Department of Economics and Management, University of Trento, Trento, Italy 